University of Nebraska - Lincoln

DigitalCommons@University of Nebraska - Lincoln

Faculty Publications in Food Science and Technology

Food Science and Technology Department

2008

\title{
Comparison of Amylose Determination Methods and the Development of a Dual Wavelength lodine Binding Technique
}

Thianming Zhu

University of Nebraska-Lincoln

David S. Jackson

University of Nebraska-Lincoln, djackson1@unl.edu

Randy L. Wehling

University of Nebraska-Lincoln, rwehling1@unl.edu

Bhima Geera

University of Nebraska-Lincoln

Follow this and additional works at: https://digitalcommons.unl.edu/foodsciefacpub

Part of the Food Science Commons

Zhu, Thianming; Jackson, David S.; Wehling, Randy L.; and Geera, Bhima, "Comparison of Amylose Determination Methods and the Development of a Dual Wavelength lodine Binding Technique" (2008). Faculty Publications in Food Science and Technology. 105.

https://digitalcommons.unl.edu/foodsciefacpub/105

This Article is brought to you for free and open access by the Food Science and Technology Department at DigitalCommons@University of Nebraska - Lincoln. It has been accepted for inclusion in Faculty Publications in Food Science and Technology by an authorized administrator of DigitalCommons@University of Nebraska - Lincoln. 


\title{
Comparison of Amylose Determination Methods and the Development of a Dual Wavelength Iodine Binding Technique ${ }^{1}$
}

\author{
Thianming Zhu, ${ }^{2}$ David S. Jackson, ${ }^{2,3}$ Randy L. Wehling, ${ }^{2}$ and Bhima Geera ${ }^{2}$
}

\section{ABSTRACT}

Cereal Chem. 85(1):51-58

It has long been recognized that limitations exist in the analytical methodology for amylose determination. This study was conducted to evaluate various amylose determination methods. Purified amylose and amylopectin fractions were obtained from corn, rice, wheat, and potato and then mixed in proportion to make $10,20,30,50$, and $80 \%$ amylose content starch samples for each source. These samples, considered amylose standards, were analyzed using differential scanning calorimetry (DSC), high-performance size-exclusion chromatography (HPSEC), and iodine binding procedures to generate standard curves for each of the methods. A single DSC standard equation for cereal starches was developed. The standard curve of potato starch was significantly different. Amylose standard curves prepared using the iodine binding method were also similar for the cereal starches, but different for potato starch. An iodine binding procedure using wavelengths at $620 \mathrm{~nm}$ and $510 \mathrm{~nm}$ increased the precision of the method. When HPSEC was used to determine $\%$ amylose, calculations based on dividing the injected starch mass by amylose peak mass, rather than calculations based on the apparent amylose/amylopectin ratio, decreased the inaccuracies associated with sample dispersion and made the generation of a cereal amylose standard curve possible. Amylose contents of pure starch, starch mixtures from different sources with different amylose ranges, and tortillas were measured using DSC, HPSEC, iodine binding, and the Megazyme amylose/amylopectin kit. All the methods were reproducible $( \pm 3.0 \%)$. Amylose contents measured by these methods were significantly different $(P<0.05)$. Amylose measurements using iodine binding, DSC, and Megazyme procedures were highly correlated (correlation coefficient $>0.95$ ). DSC and traditional iodine binding procedures likely overestimated true amylose contents as residual butanol in the amylose standards caused interference. The modified two-wavelength iodine binding procedure seemed to be the most precise and generally applicable method. Each amylose determination method has its benefits and limitations.
The end-use properties of starches are greatly influenced by the amylose/amylopectin ratio. Amylose content influences gelatinization, solubility, pasting characteristics, texture (Jane et al 1999), and the formation of resistant starch (Russel et al 1989; Bjöck et al 1990). In addition, amylose content influences loaf volume in breadbaking (Lee et al 2001). Moreover, the amylose-to-amylopectin ratio is a major parameter affecting retrogradation. Even in extrusion processing, amylose content is a consideration in controlling expansion (Chinnaswamy et al 1988). Therefore, amylose content measurement is a significant quality parameter for the majority of starch-based products.

There are many different procedures available to measure amylose. The most frequently used method is colorimetry (iodine binding with amylose); this procedure, however, is not consistently accurate because a complex forms between iodine and long chain amylopectin polymers, absorbing light at a wavelength similar to that of the amylose-iodine complex. Moreover, the existence of intermediate-sized polymers affects iodine-binding results (Himmelsbach et al 2001). Other wet-chemistry methods such as potentiometric (Bates et al 1943) or amperometric titration techniques (Williams et al 1958) are also common; these methods, however, are time-consuming. As with iodine binding methods, these procedures require a calibration standard curve using pure amylose. Some experimental evidence suggests that when measuring different sources, a standard curve needs to be generated for each source (McGrance et al 1998). When measurements involve several different sources of starch, the selection of an amylose standard curve is usually problematic.

\footnotetext{
' Contribution from University of Nebraska Agricultural Research Division, Journal Series No. 15264. Supported in part by funds provided through the Hatch Act. Mention of a trade name, proprietary products, or company name is for presentation clarity and does not imply endorsement by the authors or the University of Nebraska.

${ }^{2}$ Department of Food Science and Technology, University of Nebraska-Lincoln, Lincoln, NE 68583-0919.

${ }^{3}$ Corresponding author. Phone: (402) 472 2814. Fax: (402) 472 1693. E-mail address: djackson@unlnotes.unl.edu
}

doi:10.1094/CCHEM-85-1-0051

- 2008 AACC International, Inc.
An amylose determination method measuring enthalpy formed with a specific complex between amylose and lipo-substances using differential scanning calorimetry (DSC) has also been developed (Mestres et al 1996); this method also requires a standard curve. Another technique, the Megazyme amylose/amylopectin kit has gained in popularity. This method employs a procedure based on the specific precipitation of amylopectin by concanavalin-A lectin (Yun and Matheson 1990; Gibson et al 1995). Using the Megazyme kit, however, is a relatively long and complicated procedure. Use of the kit requires considerable training, and results are sometimes not very repeatable or the results are sensitive to nonstarch components in the sample (Gibson et al 1997). Calculating amylose content after chromatographic separation of amylose and amylopectin has appeared promising, however, variations associated with polymer dispersion and separation efficiency, as well as sample preparation conditions, can be significant (You and $\operatorname{Lim} 2000$ ).

The objective of this study was to evaluate various amylose determination methods for starches obtained from several sources with varying amylose contents.

\section{MATERIALS AND METHODS}

\section{Starches}

Regular corn starch, waxy com starch, and Amylomaize V corn starch were obtained from Cerestar USA (Hammond, IN). The regular and waxy rice starches were obtained from Remy (Leuven Wijgmaal, Belgium). Native wheat starch was obtained from Manildra Milling (Shawnee Mission, KS). Waxy wheat grain was acquired from Robert Graybosch, USDA (Lincoln, NE) and milled into flour by the Wheat Quality Lab (University of NebraskaLincoln, NE) using a Buhler experimental mill. Buccaneer hard wheat flour was obtained from ConAgra (Omaha, NE). Potato starch was obtained from Avebe (Veendam, Holland).

\section{Amylose Isolation}

Purified amylose fractions were obtained using aqueous leaching (Mua and Jackson 1998). A 3,000-mL slurry (4\% w/v) of regular corn starch, regular rice starch, or native wheat starch was heated on a hot plate to $65^{\circ} \mathrm{C}$ with continuous magnetic stirring, then held at $65^{\circ} \mathrm{C}$ (controlled within $\pm 1^{\circ} \mathrm{C}$ ) for $1 \mathrm{hr}$. The heated 
slurry was then centrifuged $(3,000 \times g, 10 \mathrm{~min})$ and the precipitate was discarded. 1-Butanol (EM Science, Gibbstown, NJ) was added to the supernatant $(1: 3 \mathrm{v} / \mathrm{v})$, mixed, and the solution was allowed to sit overnight. A pellet was then collected after centrifugation $(3,000 \times g)$ and freeze-dried to obtain the amylose fraction. Potato amylose was obtained from potato starch in a similar fashion, with the exception of heating the initial slurry at $55^{\circ} \mathrm{C}$. The purities of these isolated amylose fractions were analyzed using high-performance size-exclusion chromatography (HPSEC).

\section{Amylopectin (waxy starch) Acquisition}

Waxy wheat grain was milled into flour and the starch was obtained by hand-washing flour based on Approved Method 3810 (AACC International 2000). A firm dough was prepared by mixing $100 \mathrm{~g}$ of flour with $\approx 50 \mathrm{~mL}$ of distilled water, followed by soaking the dough ball in $2 \mathrm{~L}$ of water at room temperature for $\approx 1$ hr. At the end of incubation, the dough was hand-kneaded gently in the soak water to extract starch granules from the gluten network. The starch-water solution (with stirring) was then tabled on a $16 \mathrm{~cm} \times 3 \mathrm{~m}$ aluminum trough inclined $2 \mathrm{~cm} / 3 \mathrm{~m}$ (Wehling et al 1993). Finally, the tabled starch was allowed to air-dry.

TABLE I

List of Amylose Standard Samples and Other Starch Samples

\begin{tabular}{|c|c|}
\hline Amylose Standards & $\begin{array}{l}\text { Amylose Tests } \\
\text { Conducted }\end{array}$ \\
\hline $\begin{array}{r}\text { Corn starch with } \\
10 \% \text { Amylose } \\
20 \% \text { Amylose } \\
30 \% \text { Amylose } \\
50 \% \text { Amylose } \\
80 \% \text { Amylose } \\
\text { Wheat starch with } \\
10 \% \text { Amylose } \\
20 \% \text { Amylose } \\
30 \% \text { Amylose } \\
50 \% \text { Amylose } \\
80 \% \text { Amylose } \\
\text { Rice starch with } \\
10 \% \text { Amylose } \\
20 \% \text { Amylose } \\
30 \% \text { Amylose } \\
50 \% \text { Amylose } \\
80 \% \text { Amylose } \\
\text { Potato starch with } \\
10 \% \text { Amylose } \\
20 \% \text { Amylose } \\
30 \% \text { Amylose } \\
50 \% \text { Amylose } \\
70 \% \text { Amylose }\end{array}$ & $\begin{array}{l}\text { DSC, HPSEC, and } \\
\text { Iodine Binding }\end{array}$ \\
\hline $\begin{array}{l}\text { Other Starches } \\
\text { Amylomaize V starch } \\
\text { Waxy wheat starch } \\
\text { Wheat flour } \\
\text { Wheat starch } \\
\text { Nondefatted tortilla } \\
\text { Defatted tortilla } \\
\text { Amylomaize V + wheat starch } \\
\text { Wheat starch + waxy wheat starch }\end{array}$ & $\begin{array}{c}\text { DSC, HPSEC } \\
\text { Megazyme Amy/Amp } \\
\text { Kit \& Iodine Binding }\end{array}$ \\
\hline $\begin{array}{l}\text { Combined samples } \\
\text { Pectin, Quinoa Starch, Sorghum Starch, Corn } \\
\text { Pregelatinized Starch, Potato Pregelatinized } \\
\text { Starch, Waxy Wheat Starch, Native Wheat } \\
\text { Starch, Wheat Starch + Linoleic Acid, Wheat } \\
\text { Starch + Sugar, Wheat Starch + Salt, Waxy } \\
\text { Corn Starch, Corn Starch + Stearic Acid, Amy- } \\
\text { lomaize V Starch + NaCl/Sucrose/BSA, Corn } \\
\text { Masa Flour }\end{array}$ & DSC Only \\
\hline
\end{tabular}

To obtain a potato amylopectin fraction, the potato amylose extraction procedure outlined above was performed, but the first precipitated pellet was retained. This pellet was resuspended and maintained at $55^{\circ} \mathrm{C}$ for $0.5 \mathrm{hr}$ with stirring. Then the resuspended solution was centrifuged $(3,000 \times g, 10 \mathrm{~min})$. The resuspension and centrifugation process was repeated five times. The final pellet was freeze-dried as potato amylopectin.

Waxy corn and rice starches, as mentioned previously, were directly used from their commercial sources. The purity of amylopectin fractions obtained from each source was monitored using HPSEC.

\section{Sample Preparation for Amylose Analysis}

To analyze and estimate the general applicability of the various amylose testing methods, samples with different chemical characteristics were tested (Table I). For the DSC testing, starches from various sources, pregelatinized starch, pectin, and corn masa were randomly mixed with lipid (linoleic and stearic acid), protein (BSA), salt $(\mathrm{NaCl})$, or sugar. These preparations were analyzed using DSC based on a constant starch weight $(10 \approx 12 \mathrm{mg})$ to subjectively assess the applicability of DSC amylose measuring method using different starch sources and with other food components (Table I).

For all amylose testing methods, samples were prepared in common to aid in the evaluation of the applicability of the amylose procedures (Table I). A model food system (tortillas) was prepared. Buccaneer wheat flour (ConAgra) was selected for tortilla preparation. The formula used was $1,000 \mathrm{~g}$ of flour (as-is basis), $17 \mathrm{~g}$ of salt, $3 \mathrm{~g}$ of sodium-2-stearoyl lactylate (SSL), $6 \mathrm{~g}$ of potassium sorbate, $8 \mathrm{~g}$ of baking powder, $2 \mathrm{~g}$ of fumaric acid, $80 \mathrm{~g}$ of vegetable shortening, and $533 \mathrm{~mL}$ of water. The mixed dough was machine-cut, hot-pressed $(0.8 \mathrm{sec}$ with both plates set at $196^{\circ} \mathrm{C}$ ), and baked $40 \mathrm{sec}$ in a gas-fired, three-pass, continuous tortilla baking oven (micro combo with pressing head, model OPO1004-07, Lawrence Equipment, El Monte, CA) maintained at $204^{\circ} \mathrm{C}$. After baking, tortillas were passed through a cooling conveyer (model OCC1208-03, Lawrence Equipment), freeze-dried, and then ground. A portion of each ground tortilla sample was defatted.

Buccaneer wheat starch was extracted from Buccaneer wheat flour following the same procedure as for waxy wheat starch. Amylomaize V starch (Cerestar USA, Hammond, IN) and Buccaneer wheat starch, or Buccaneer wheat starch with waxy wheat starch, were mixed 1:1 on a wet basis to make starch samples that represent mixing of different sources and mixing of different amylose contents. Amylose contents of these samples were determined using DSC, HPSEC, iodine binding, and Megazyme amylose/amylopectin assay kit methods (Table I).

High-Performance Size-Exclusion Chromatography (HPSEC)

The purities of amylose and amylopectin fractions were monitored using HPSEC. HPSEC was also used to measure \% amylose based on the detected amylose or amylopectin (peak areas/mass). Samples were dispersed using $90 \%$ DMSO and placed in a boiling water bath for $1 \mathrm{hr}$ with frequent vortexing (medium setting) to obtain a $1 \% \mathrm{w} / \mathrm{v}$ clear solution. A dispersion time of $30 \mathrm{~min}$ was also tested for corn and wheat $20 \%$ amylose standards. After dispersion, samples were filtered through a $1.2-\mu \mathrm{m}$ nylon filter. The resulting starch solution $(20 \mu \mathrm{L})$ was injected into an HPSEC system consisting of 4 KS-series Shodex Ionpak columns (Showa Denko, Tokyo, Japan) connected in series to a refractive index detector (Waters model 410, Millipore Co., Milford, MA) and subsequently in-line to a DAWN-SF multiple angle laser light scattering (MALLS) photometer (Wyatt Technology, Santa Barbara, CA). Deionized water $(1.0 \mathrm{~mL} / \mathrm{min})$ was used as the mobile phase. Amylose and amylopectin fraction peaks were collected and analyzed using ASTRA software (v.4.70.07, Wyatt Technology, Santa Barbara, CA) for peak areas and calculation of the polymer mass corresponding to each peak. 


\section{Differential Scanning Calorimetry (DSC)}

Samples (mixed dry as appropriate) were weighed into large (60 $\mathrm{mL}$ capacity) DSC aluminum pans (part no. 0319-1526, Perkin Elmer, Norwalk, CT) and allowed to equilibrate for at least $2 \mathrm{hr}$ after addition of a $50-\mu \mathrm{L}, 2 \% \mathrm{~L}-\alpha$-Lysophosphatidylcholine (LPC, Type I from egg yolk, Sigma) distilled water solution to hydrate starch samples. Moisture contents of starch samples were measured (Approved Method 44-15A, AACC International 2000) to calculate dry matter weight placed in each DSC pan. Calorimetric measurements were performed using a Perkin Elmer Pyris 1 DSC (Perkin Elmer, Norwalk, CT) with an empty pan as a reference. The DSC system was calibrated using an indium reference. Samples were heated from 35 to $125^{\circ} \mathrm{C}$ at $15^{\circ} \mathrm{C} / \mathrm{min}$, held at $125^{\circ} \mathrm{C}$ for $2 \mathrm{~min}$, and cooled to $60^{\circ} \mathrm{C}$ at $10^{\circ} \mathrm{C} / \mathrm{min}$ (Mestres et al 1996). The exotherm emitted during the cooling phase, which represents LPCamylose complex formation, was measured and analyzed using Pyris software for Windows (v.3.52).

\section{Iodine Binding}

Samples containing $100.0 \pm 0.1 \mathrm{mg}$ of dry substance were weighed and transferred into a $100-\mathrm{mL}$ volumetric flask. Ethyl alcohol $(1 \mathrm{~mL})$ was added to wet the sample. Then $10 \mathrm{~mL}$ of $1 N$ sodium hydroxide solution was added, swirled to disperse the sample, and allowed to rest $\approx 1 \mathrm{hr}$ until the sample solution was completely clear and free of lumps. Then it was diluted to volume with distilled water, after which $2 \mathrm{~mL}$ of this dilution was pipetted to another $100-\mathrm{mL}$ volumetric flask. Water $(\approx 50 \mathrm{~mL})$ and two drops of phenothalein indicator were added. Hydrochloric acid $(0.1 N)$ was used to titrate the solution to neutral. Then $2.0 \mathrm{~mL}$ of $0.2 \%$ iodine solution $(2.0 \mathrm{~g}$ of potassium iodide and $0.2 \mathrm{~g}$ of iodine diluted to $100 \mathrm{~mL}$ with distilled water) was added; the flask was filled to volume. This final solution was allowed to sit $30 \mathrm{~min}$ to fully develop color and the sample was subsequently scanned through the visible and short-wave near infrared regions $(400 \approx$ $1100 \mathrm{~nm}$ at $2-\mathrm{nm}$ intervals) in a $1.0-\mathrm{cm}$ quartz cell using a spectrometer (NIRSystems model 6500, Silver Spring, MD). The wavelengths yielding the highest linear regression coefficients were selected by the Near Infrared Spectral Analysis System software (v3.53, FOSS NIRSystems, Silver Spring, MD).

\section{Megazyme Amylose/Amylopectin Assay Kit}

The procedure outlined by the manufacturer for the Megazyme amylose/amylopectin assay kit was strictly followed. \% Amylose was directly calculated following the specific Megazyme equation based on the measured absorbance values; no additional standard curve or equation was generated for this study.

\section{Amylose Standards}

Amylose and amylopectin fractions were ground using an A-10 analytical mill (Tekmar, Cincinnati, $\mathrm{OH}$ ). Moisture contents were measured according to Approved Method 44-15A (AACC International 2000). Amylose and amylopectin fractions were mixed to make $10,20,30,50$, and $80 \%$ (w/w, dry basis) amylose content samples within each source (potato $70 \%$ instead of $80 \%$ due to a sample limitation). Each amylose standard was analyzed using DSC, HPSEC, and iodine binding (blue value) amylose content tests (Table I) to generate the standard curves for each starch source. Due to the interference of trace amounts of butanol, the amylose standards did not yield reasonable results when measured with the Megazyme amylose/amylopectin assay kit; the color reaction yielded an odd dark red hue. Generally, standard curves were produced using the known amylose percents on the $x$ axis $(10,20,30,50$, and $80 \% ; 70 \%$ for potato) and the responses (e.g., enthalpy for DSC, absorbance for iodine binding) as the $y$ axis. The samples were analyzed three times by each of the three methods. In each method, 20 samples ( 5 from each source) were measured following a completely randomized block design with replicate as a block.

\section{Statistical Design and Analysis}

For the standard curve generation experiments, a randomized complete block design was applied with three replicates (blocks) per amylose standard per method (HPSEC, DSC, iodine binding). When the four different methods (HPSEC, DSC, iodine binding, and Megazyme) were compared, a randomized complete block design (operating day as block) was used with four replicates (four days) per sample per method. Statistical analysis was performed using SAS software (v.8.00, SAS Institute, Cary, NC). Least significant difference (LSD) tests, analysis of covariance, analysis of homogeneity of regression coefficients, $t$-tests, analysis of variance (ANOVA), and analysis of correlation were performed. When comparing the four methods, measured responses for DSC, iodine binding, and HPSEC were plugged into the corresponding standard equation to predict $\%$ amylose. Precision was expressed using a $95 \%$ confidence interval for mean predicted $\%$ amylose value (fiducial confidence interval).

\section{RESULTS AND DISCUSSION}

Pure amylose fractions were obtained by the process of aqueous leaching from each source; amylopectin fractions obtained were also quite pure as measured by HPSEC (Fig. 1). The fractions were substantially more pure than a commercial potato amylose preparation. These amylose/amylopectin fractions were treated

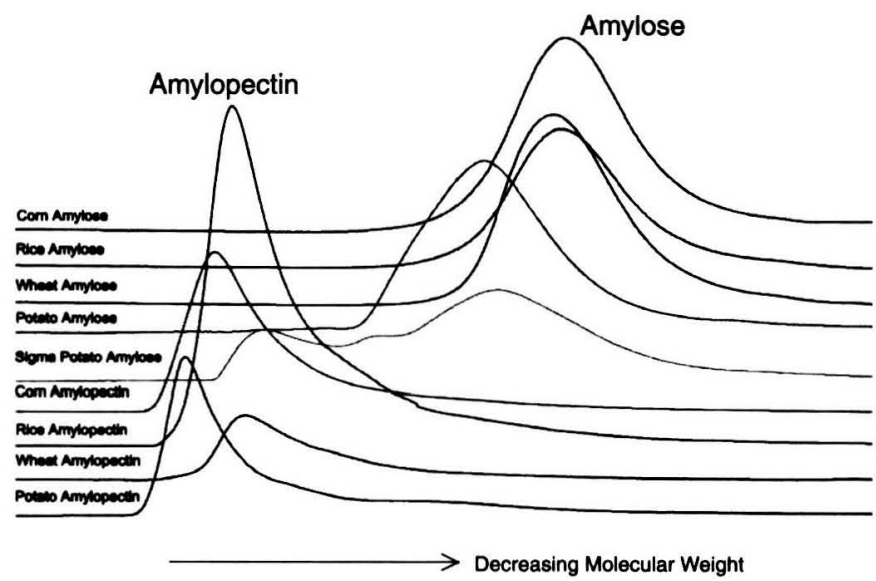

Fig. 1. High-performance size-exclusion chromatography (HPSEC) profiles of purified amylose and amylopectin fractions measured using a refractive index detector with retention time $(\min )$ as the $x$-axis and refractive index difference $(\mathrm{mV})$ as the $y$-axis.

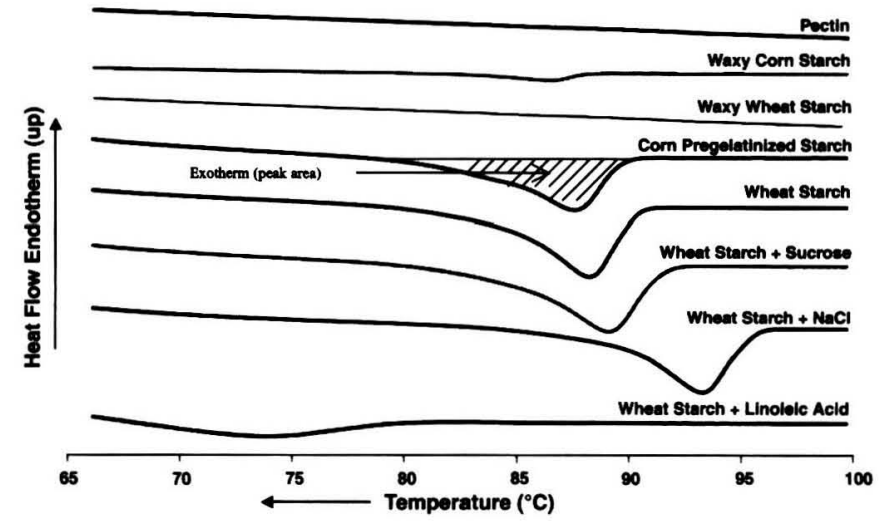

Fig. 2. Differential scanning calorimetry (DSC) responses for different starch sources and systems during DSC amylose measurement. Peaks (exotherms) were formed during the cooling phase. Values for exotherms were calculated on the basis of peak area $(\mathrm{J} / \mathrm{g})$. Starch samples tested had the same starch content $( \pm 0.2 \mathrm{mg})$. 
as pure components and then used and mixed together in certain ratios to make standard samples with known amounts of amylose.

\section{Evaluation of Methods and Standard Curves Generation}

DSC. Samples for the DSC measurement were easy to prepare. The method is not time-consuming for individual samples. Multiple samples, however, cannot be measured simultaneously; if large numbers of sample need to be analyzed, the minimum 20 min/run becomes a disadvantage. The interaction between LPC and amylose was specific. As characterized by a DSC enthalpy value, neither amylopectin from waxy wheat, amylopectin from waxy rice, nor pectin formed a complex with LPC. There was a small enthalpy value associated with the waxy corn starch-LPC mixture, as well as with potato amylopectin. The addition of lipid or protein changed the DSC peak shape. Addition of lipid shifted and reduced the peak area dramatically (Fig. 2). The peak temperature of amylose-LPC complex formation was subject to starch source and sample composition (Table II). For example, starches from corn yielded higher peak temperatures than potato or quinoa; addition of lipid lowered the peak temperature. The blocked parameter (DSC run) did not have any significant effect $(P=$ 0.4931 ); analysis was then treated as a complete random design (CRD). Standard curves were generated using known \% amylose as the $x$-axis and the measured responses, which were enthalpies, as the $y$-axis. For each starch source, the DSC method had a linear response over a wide range of $\%$ amylose $\left(R^{2}>0.97\right)$ (Fig. 3). Slopes of corn, rice, and wheat starch curves were not statistically different $(P=0.1825)$, and the mean response of the three cereal sources at equivalent amylose contents did not differ $(P=0.776)$. Therefore, standard curves for these three sources could be treated as identical; an overall standard curve for cereal starch sources was generated (Eq. 1)

$$
\begin{aligned}
& \text { Cereal sources: } \% \text { Amylose }=(\text { enthalpy }+0.4881) /-16.104 \\
& R^{2}=0.99
\end{aligned}
$$

The slope of the potato starch standard curve, however, was significantly different $(P<0.0001)$ relative to that of the cereal starches. As the potato starch standard curve differed, its equation is shown as Eq. 2

$$
\begin{gathered}
\text { Potato: \% Amylose }=(\text { enthalpy }+1.8191) /-20.337 \\
\qquad R^{2}=0.99
\end{gathered}
$$

lodine binding. The iodine binding procedure, when compared to the DSC method, requires more steps and more precise control.

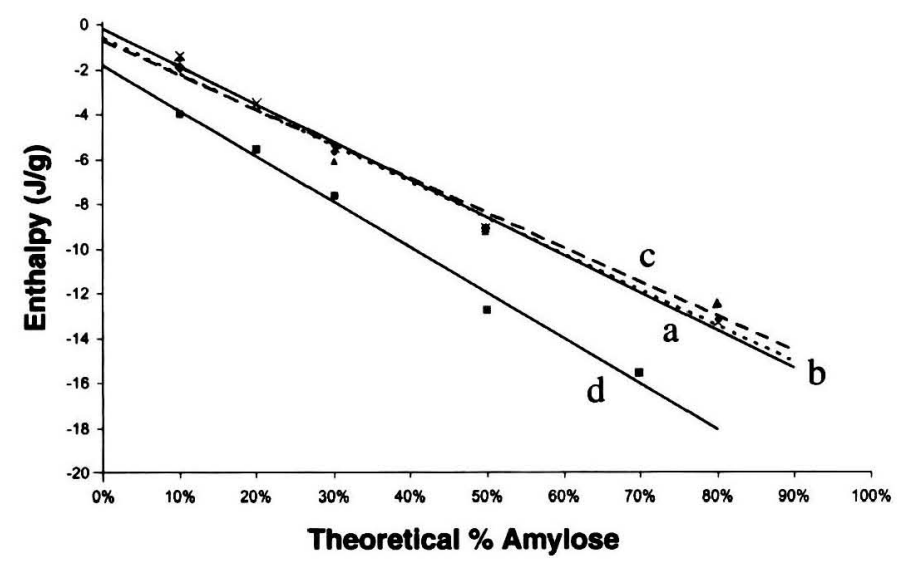

Fig. 3. Differential scanning calorimetry (DSC) standard curves. Each starch source was generated using starch sample mixtures with known amylose contents. (a) Wheat $y=-16.845 x-0.1601\left(R^{2}=0.9941, n=15\right)$. (b) Com $y$ $=-16.065 x-0.5826\left(R^{2}=0.9952, n=15\right)$. (c) Rice $y=-15.402 x-0.7217$ $\left(R^{2}=0.9762, n=15\right)$. (d) Potato $y=-20.337 x-1.8191\left(R^{2}=0.9903, n=\right.$ 15). Slopes and mean values for a, b, c were not significantly different $(P$ $=0.183$ and $\pm P=0.776$, respectively).
Its advantage is that multiple samples can be analyzed simultaneously; the total run time can be shorter than the DSC procedure when sample numbers are approximately $\geq 10$.

The blocked parameter (batch) was not significant $(P=0.2112)$; iodine binding analysis was based on a CRD. Following the commonly used procedure, the $620 \mathrm{~nm}$ wavelength was selected to measure the amylose-iodine complex light absorption. Standard curves were created using theoretical \% amylose as the $x$-axis and absorbance as the $y$-axis. As with the DSC procedure, curves from cereal sources were not significantly different both in slope $(P=$ $0.7921)$ and mean absorption within the measured amylose range $(P=0.1589)$. An overall standard curve was generated for cereal starches (Eq. 3) and a standard curve for potato starch was created separately (Eq. 4). The prediction confidence interval associated with this method, however, was bigger than for the DSC procedure, with a weaker linear relationship when measuring each source ( $R^{2}$ values of $0.964,0.985,0.973$, and 0.927 for corn, rice, wheat, and potato, respectively) (Fig. 4)

$$
\begin{aligned}
& \text { Cereal sources: \% Amylose }=(\mathrm{ABS}-0.2072) / 0.5669 \\
& R^{2}=0.9739 \\
& \\
& \text { Potato: \% Amylose }=(\mathrm{ABS}-0.2601) / 0.7511 \\
& R^{2}=0.9268
\end{aligned}
$$

Because the starch samples were continuously scanned at wavelengths between 400 and $1100 \mathrm{~nm}$, absorption values for each wavelength were collected for every amylose standard. Two wavelengths representing the absorption peak and the adjacent valley are 620 and $510 \mathrm{~nm}$, respectively (Fig. 5). When a single wavelength was selected by linear regression for each starch source, the selected wavelength yielding the highest regression coefficient was always close to $620 \mathrm{~nm}$. When a second wavelength was

TABLE II

Effect of Starch Source and Sample Composition on DSC LPC-Amylose Complex Formation Temperatures ${ }^{\mathrm{a}}$

\begin{tabular}{lc}
\hline Sample & Mean Peak Temp $\left({ }^{\circ} \mathrm{C}\right)$ \\
\hline Amylomaize V starch (corn) $+\mathrm{NaCl}$ & $93.73 \mathrm{a}$ \\
Masa (corn) & $89.33 \mathrm{~b}$ \\
Amylomaize V starch (corn) + sucrose & $88.83 \mathrm{~b}$ \\
Amylomaize V starch (corn) + BSA & $88.60 \mathrm{~b}$ \\
Corn pregelatinized starch & $88.47 \mathrm{~b}$ \\
Potato pregelatinized starch & $86.22 \mathrm{c}$ \\
Quinoa starch & $85.77 \mathrm{c}$ \\
Sorghum starch & $85.73 \mathrm{c}$ \\
Corn starch + stearic acid & $78.68 \mathrm{~d}$ \\
\hline
\end{tabular}

${ }^{a}$ Means (average of 3 runs) with the same letter were not significantly different $(\alpha<0.05)$.

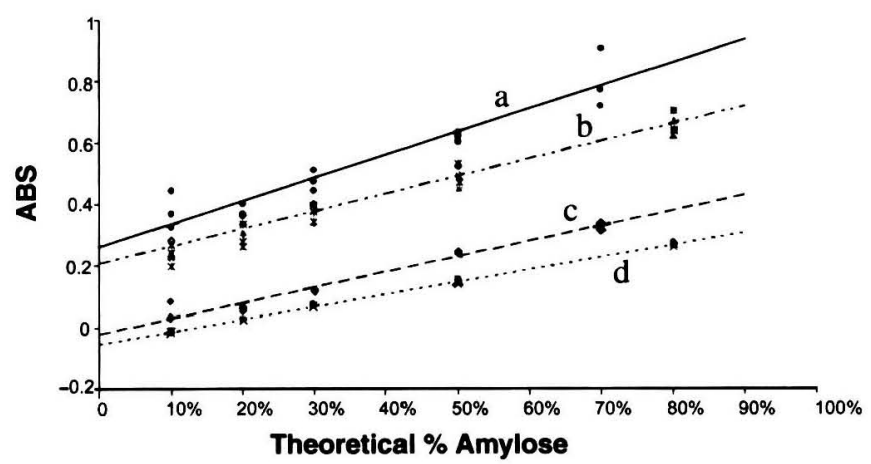

Fig. 4. Standard curves of different starch sources using the iodine binding procedure to measure amylose content. Comparison between using traditional $620 \mathrm{~nm}$ single wavelength vs. using $620 \mathrm{~nm} / 510 \mathrm{~nm}$ dual wavelengths. (a) Standard curve for potato starch $(620 \mathrm{~nm}$ single). (b) Standard curve for cereal starch sources $(620 \mathrm{~nm}$ single). (c) Standard curve for potato starch $(620 / 510 \mathrm{~nm}$ dual). (d) Standard curve for cereal starch sources $(620 / 510 \mathrm{~nm}$ dual $)$. 
added to create a two-wavelength regression model, the wavelength picked by the software that gave the highest regression coefficient for each source was close to $510 \mathrm{~nm}$. When the differences of the ABS values between these two wavelengths were used to perform a linear regression, rather than the single ABS value at $620 \mathrm{~nm}$, the testing precision and linear relationship were improved $\left(R^{2}\right.$ values of $0.9995,0.9995,0.9996$, and 0.9799 , for corn, rice, wheat, and potato, respectively) (Fig. 4). Alternative standard curves were created using these two wavelengths. As with the $620 \mathrm{~nm}$ method, standard curves for cereal sources had slopes that were not statistically different $(P=0.5072)$ and had responses that were not statistically different within the ranges of amylose contents tested $(P=0.1481)$; potato behaved differently. Based on these results, using the additional $510 \mathrm{~nm}$ test wavelength is suggested when using the iodine binding procedure to measure \% amylose. With the simple addition of this experimental step and the associated calculation, the precision was enhanced. These new prediction equations are Eqs. 5 and 6, where Diff ABS indicates the difference between the absorbance value at 620 and $510 \mathrm{~nm}\left(\mathrm{ABS}_{620}-\mathrm{ABS}_{510}\right)$

Cereal sources: \% Amylose $=($ Diff ABS + 0.0542 $) / 0.3995$

$$
R^{2}=0.9999
$$

Potato: \% Amylose $=($ Diff ABS +0.0203$) / 0.5002$

$$
R^{2}=0.9799
$$

HPSEC. The HPSEC method is simple to operate. As measured using this procedure, the responses are straightforward; the tested $\%$ amylose could be calculated directly based on the peak areas from a chromatographic profile by dividing the amylose peak area by total starch peak area (amylose peak plus amylopectin peak). However, due to the associated problem of poor starch polymer dispersion (Jackson 1991), the measured values can vary from the "true" values. Therefore, to precisely predict an unknown sample, standard curves using known \% amylose vs. measured \% amylose were generated for each starch source.

Within each starch source, the HPSEC procedure had a linear response over a wide range of \% amylose $\left(R^{2}>0.97\right)$; and block effects (runs) were not significant $(P=0.4597)$. Unlike the results for the DSC or iodine binding procedure, the slopes for all four starch sources were identical $(P=0.5118)$. The mean response of the starch from each source however, at any given amylose content, was significantly different $(P<0.0001)$ (Fig. 6A); there was a parallel shift in response (measured \% amylose) among the starch sources. Hence, to measure the amylose content from different starch sources, a standard curve generated from that source should be used. However, when measuring unknown starches or mixed samples, there would be no single appropriate standard curve to select. This makes this procedure less universally applicable. Standard curves from corn and wheat sources, however, were not significantly different $(P<0.05)$. To easily compare the HPSEC

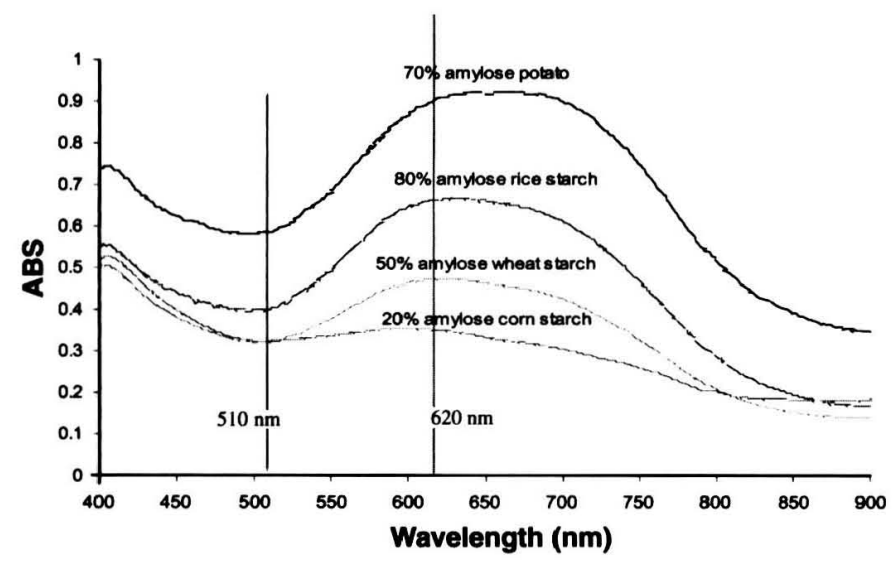

Fig. 5. Profile of visible spectral scan of iodine binding with amylose. data with those of the other amylose procedures (where corn and wheat sources were used), a combined standard curve for corn and wheat sources was generated (Eq. 7)

$$
\begin{gathered}
\text { Corn and wheat: Actual \% amylose }= \\
\text { (measured \% amylose }-0.1185) / 0.9687 \\
R^{2}=0.9743
\end{gathered}
$$

In addition to the peak area ratio calculation $\mathrm{A}$ [amylose/ (amylose + amylopectin)] using the calculated peak mass from ASTRA, as described above, calculation B based on (amylose mass/injected starch mass) was also performed. The injected starch mass needed to be calculated based on sample mass weighed. The ability to estimate peak mass for the HPSEC system was also a requirement. Again, the linear relationships over the tested amylose range were obtained for all sources $\left(R^{2}>0.97\right)$ (Fig. 6B). Likewise, slopes used for the four starch sources were not statistically different $(P=0.1157)$. Using this calculation method, however, mean responses at any measured amylose range for the three cereal sources were not statistically different $(P=0.0748)$. Thus a prediction equation for cereal starch sources could be generated (Eq. 8) that increased the applicability of the HPSEC method when analyzing cereal starch mixtures.

$$
\begin{gathered}
\text { Cereal sources: Actual \% amylose }= \\
\text { (measured \% amylose }-0.0084) / 0.1454 \\
R^{2}=0.9909
\end{gathered}
$$

Because amylose is more easily dispersed into the HPSEC injected solution than amylopectin (Jackson 1991), calculation A tended to overestimate sample amylose values. However, calcula-
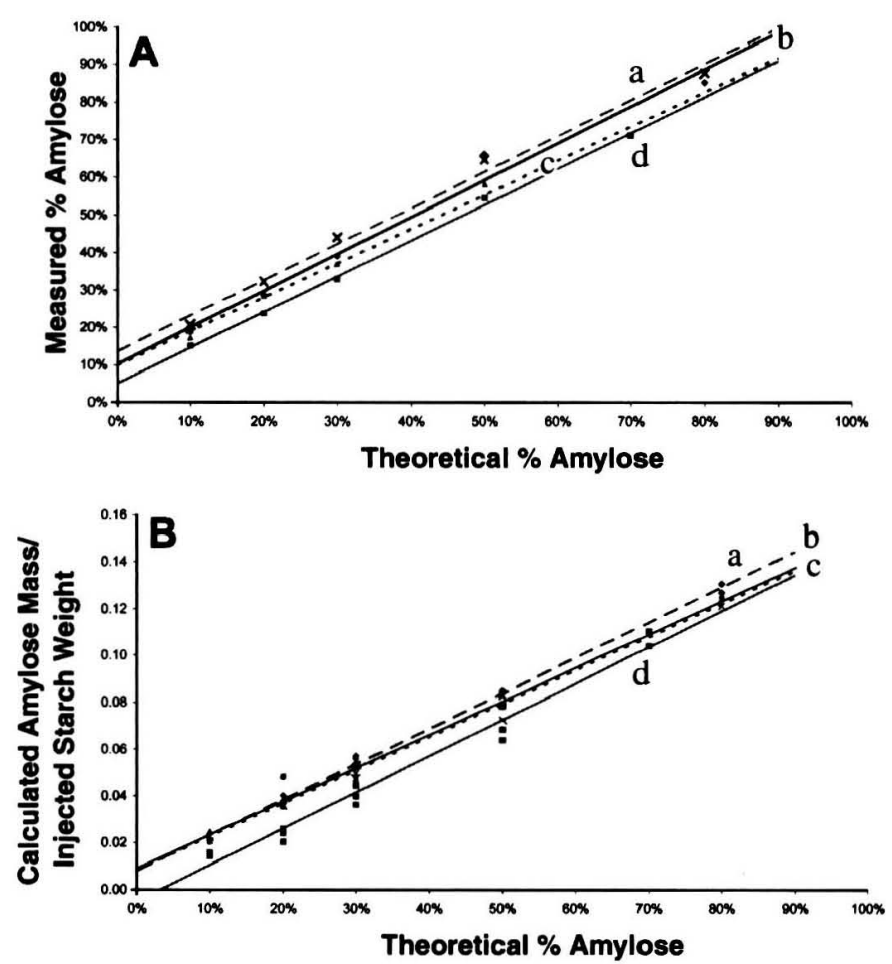

Fig. 6. High-performance size-exclusion chromatography (HPSEC) standard curves. Each starch source was generated using starch sample mixtures with known amylose contents. A, Area ratio of [amylose/(amylose + amylopectin)] from chromatography profile as response. (a) Wheat $y=$ $0.9567 x+0.1348\left(R^{2}=0.9905, n=15\right)$. (b) Corn $y=0.9807 x+0.1022$ $\left(R^{2}=0.9791, n=15\right)$. (c) Rice $y=0.9084 x+0.098\left(R^{2}=0.9943, n=\right.$ 15). (d) Potato: $y=0.9537 x+0.0501\left(R^{2}=0.9967, n=15\right)$. B, Alternative standard curves [machine calculated amylose mass/injected total starch weight] as response. (a) Corn $y=0.1513 x+0.08\left(R^{2}=0.9911, n=\right.$ 15). (b) Wheat $y=0.1427 x+0.0089\left(R^{2}=0.9882, n=15\right)$. (c) Rice $y=$ $0.1422 x+0.082\left(R^{2}=0.9962, n=15\right)$. (d) Potato $y=0.1546 x+0.0048$ $\left(R^{2}=0.9817, n=15\right)$. 
tion method B reduced the degree of overestimation and susceptibility to dispersion conditions. When dispersion time was reduced to $30 \mathrm{~min}$ from the original $1 \mathrm{hr}$, calculation B amylose content values were much more reliable. For a $20 \%$ amylose corn starch, the calculated amylose values were $32.0 \%$ vs. $17.4 \%$ (A vs. B); for a $20 \%$ amylose wheat starch, the calculated amylose values were $35.3 \%$ vs. $21.2 \%$ (A vs. B) (average of two samples each).

\section{Precision, Accuracy, and Method Comparisons}

Simple starch samples, samples representing mixtures of different starch sources, and a processed food system were analyzed using four different procedures: DSC, iodine binding, HPSEC, and the Megazyme amylose/amylopectin kit (Table III). All of these four methods appeared to be reproducible with deviations (95\% confidence interval) $<5 \%$. Using dual wavelengths, the iodine binding method had a greatly increased precision with the deviation limited to $\pm 0.5 \%$. Using the Megazyme amylose/amylopectin kit, however, deviations of the mean measured value were the biggest among the methods (minimum 1.6\%, maximum 4.6\%).

The measured values using the DSC and traditional iodine binding $(620 \mathrm{~nm})$ procedures tended to be higher than those reported in literature. There are two possible reasons for the inflation of amylose content values. The standard curves were generated using aqueous leached, mostly linear amylose containing samples. These amylose polymers tend to have lower molecular weights than the normal distribution of amylose polymers found in starches; and hence, may bind less lipid or iodine. Another reason might be that because the standard amylose polymers were precipitated with butanol, that the remaining butanol-amylose complex might inhibit LPC or iodine binding with amylose. Likely, LPC-amylose binding was inhibited more than iodine because the larger size of LPC compared with iodine would require more free amylose helices to bind. Thus, during the reaction in the procedure, one unit (hypothetically) of LPC or iodine might only complex with one unit of purified amylose (butanol-amylose) but 1.5 units of native amylose (a similar result possibly would happen when dealing with nondefatted starches containing lipid that occupies amylose helices). Regardless, these two methods appear to over- estimate amylose contents when measuring the native amylose, especially the DSC procedure. As these two procedures were very reproducible and had linear relationships over a range of amylose contents, amylose determination could be performed with other amylose standards or be adjusted accordingly. When using dual wavelengths $(620 / 510 \mathrm{~nm})$ in the iodine binding method, the overestimation effect was reduced or eliminated, and the amylose content values calculated were close to those commonly reported in the literature.

The HPSEC method, using either calculation A or B, appeared to be unreliable, especially when measuring impure starch samples. This was most likely due to the associated sample dispersion problem (Jackson 1991). Amylose and amylopectin polymers were more difficult to disperse into solution in the presence of other components. Leached amylose standards used to generate standard curves were easier to disperse. Hence, the measured amylose values using calculation $B$ tended to be lower than those calculated using DSC or the iodine binding procedures. When measuring pure starch samples, however, if the consistency of the dispersing procedure was well controlled or optimized, the direct calculation method $\mathrm{A}$ has potential.

The four amylose determination methods using this set of samples yielded significantly different results $(P<0.0001)$. Generally, among the various methods, amylose values calculated using the dual wavelength iodine binding procedure were closest to those commonly anticipated; the values were compared with those from other amylose methods (Table IV). Also, as it had the highest precision, this dual wavelength iodine binding procedure was considered the most appropriate amylose measuring method. The DSC, traditional iodine binding $(620 \mathrm{~nm})$, and Megazyme procedures, however, were highly correlated. Correlation coefficients were $0.975\left(\mathrm{DSC} / \mathrm{I}_{2} 620\right), 0.959$ (DSC/Megazyme), and $0.965\left(\mathrm{I}_{2}\right.$ 620/ Megazyme). When using starches with known amylose values as amylose standards, measured results are not likely to be different for the three procedures.

As discussed above, the aqueous leached and butanol precipitated amylose standards used in the DSC, iodine binding, and HPSEC methods caused the measured \% amylose to vary from

TABLE III

Comparison of \% Amylose Values from Six Different Methods*

\begin{tabular}{|c|c|c|c|c|c|c|c|}
\hline Sample & $\begin{array}{c}\text { Anticipated \% } \\
\text { Amylose } \dagger\end{array}$ & $\mathrm{DSC}^{\mathrm{a}, \mathrm{c}}$ & $\begin{array}{c}\text { Iodine } \\
(620 \mathrm{~nm})^{\mathrm{a}, \mathrm{c}}\end{array}$ & $\begin{array}{l}\text { Iodine Dual } \\
(620 / 510)^{a, c}\end{array}$ & $\begin{array}{c}\text { HPSEC } \\
\operatorname{Cal}(\mathbf{A})^{\mathbf{b}, \mathbf{c}}\end{array}$ & $\begin{array}{c}\text { HPSEC } \\
\text { Cal }(B)^{a, c}\end{array}$ & Megazyme $^{d}$ \\
\hline Amylomaize V starch & $48-53$ & $\begin{array}{l}63.9 \% \\
(62.5 \%, 65.4 \%)\end{array}$ & $\begin{array}{l}69.5 \%^{\mathrm{e}} \\
(67.4 \%, 71.6 \%)\end{array}$ & $\begin{array}{l}48.6 \% \text { f } \\
(48.4 \%, 48.8 \%)\end{array}$ & $\begin{array}{l}45.4 \%^{f} \\
(45.2,45.6 \%)\end{array}$ & $\begin{array}{l}35.2 \% \\
(34.5 \%, 36.0 \%)\end{array}$ & $\begin{array}{l}42.4 \% \mathrm{f} \\
(35.3 \%, 45.4 \%)\end{array}$ \\
\hline Waxy wheat starch & 0 & $\begin{array}{l}-3.0 \% \\
(-5.0 \%,-1.2 \%)\end{array}$ & $\begin{array}{l}8.9 \% \\
(6.9 \%, 10.9 \%)\end{array}$ & $\begin{array}{l}1.5 \% \\
(1.2 \%, 1.8 \%)\end{array}$ & $\begin{array}{l}-12.2 \% \\
(-12.6 \%,-11.9 \%)\end{array}$ & $\begin{array}{l}-5.8 \% \\
(-7.3 \%,-4.3 \%)\end{array}$ & $\begin{array}{l}4.4 \% \mathrm{j} \\
(1.9 \%, 7.0 \%)\end{array}$ \\
\hline Wheat flour & $19-24$ & $\begin{array}{l}33.6 \% \\
(32.6 \%, 34.6 \%)\end{array}$ & $\begin{array}{l}28.1 \% \\
(26.7 \%, 29.5 \%)\end{array}$ & $\begin{array}{l}22.9 \%^{\mathrm{g}} \\
(22.7 \%, 23.1 \%)\end{array}$ & $\begin{array}{l}22.8 \% \mathrm{~g} \\
(22.6 \%, 23.0 \%)\end{array}$ & $\begin{array}{l}4.7 \% \\
(3.5 \%, 5.9 \%)\end{array}$ & $\begin{array}{l}19.9 \% \mathrm{~g} \\
(15.7 \%, 24.1 \%)\end{array}$ \\
\hline Wheat starch & $25-30$ & $\begin{array}{l}46.8 \% \\
(45.8 \%, 47.9 \%)\end{array}$ & $\begin{array}{l}40.1 \% \\
(38.8,41.4 \%)\end{array}$ & $\begin{array}{l}31.4 \%^{\mathrm{h}} \\
(31.2 \%, 31.5 \%)\end{array}$ & $\begin{array}{l}27.0 \%{ }^{\mathrm{h}, \mathrm{i}} \\
(26.8 \%, 27.2 \%)\end{array}$ & $\begin{array}{l}18.9 \% \\
(18.0 \%, 20.0 \%)\end{array}$ & $\begin{array}{l}24.0 \% \\
(22.4 \%, 25.6 \%)\end{array}$ \\
\hline $\begin{array}{l}\text { Wheat starch + waxy } \\
\text { wheat starch }\end{array}$ & $13-17$ & $\begin{array}{l}16.2 \% \mathrm{k} \\
(14.5 \%, 17.9 \%)\end{array}$ & $\begin{array}{l}22.4 \% \\
(20.9 \%, 24.0 \%)\end{array}$ & $\begin{array}{l}16.0 \%^{\mathrm{k}} \\
(15.7 \%, 16.2 \%)\end{array}$ & $\begin{array}{l}10.8 \% \\
(10.5 \%, 11.0 \%)\end{array}$ & $\begin{array}{l}6.5 \% \\
(5.3 \%, 7.7 \%)\end{array}$ & $\begin{array}{l}13.1 \%^{k} \\
(9.5 \%, 16.7 \%)\end{array}$ \\
\hline $\begin{array}{l}\text { Amylomaize V + wheat } \\
\text { starch }\end{array}$ & $37-42$ & $\begin{array}{l}56.5 \% \\
(55.3 \%, 57.7 \%)\end{array}$ & $\begin{array}{l}50.9 \% \\
(49.4 \%, 52.3 \%)\end{array}$ & $\begin{array}{l}41.0 \% \mathrm{~m} \\
(40.8 \%, 41.1 \%)\end{array}$ & $\begin{array}{l}41.1 \%{ }^{\mathrm{m}} \\
(40.9 \%, 41.3 \%)\end{array}$ & $\begin{array}{l}25.3 \% \\
(24.5 \%, 26.2 \%)\end{array}$ & $\begin{array}{l}34.8 \%^{\mathrm{m}} \\
(30.4 \%, 39.1 \%)\end{array}$ \\
\hline Nondefatted tortilla & $17-21$ & $\begin{array}{l}31.3 \% \\
(30.3 \%, 32.3 \%)\end{array}$ & $\begin{array}{l}23.4 \%^{\mathrm{n}} \\
(21.9 \%, 24.9 \%)\end{array}$ & $\begin{array}{l}19.5 \%^{n} \\
(19.3 \%, 19.7 \%)\end{array}$ & $\begin{array}{l}62.6 \% \\
(62.4 \%, 62.8 \%)\end{array}$ & $\begin{array}{l}11.0 \% \\
(9.9 \%, 12.1 \%)\end{array}$ & $\begin{array}{l}22.6 \% n \\
(19.9 \%, 25.4 \%)\end{array}$ \\
\hline Defatted tortilla & $18-23$ & $\begin{array}{l}32.3 \% \\
(31.3 \%, 33.4 \%)\end{array}$ & $\begin{array}{l}26.3 \%^{\circ} \\
(24.9 \%, 27.7 \%)\end{array}$ & $\begin{array}{l}22.5 \%^{\circ} \\
(22.3 \%, 22.7 \%)\end{array}$ & $\begin{array}{l}28.3 \%^{\circ} \\
(28.1 \%, 28.4 \%)\end{array}$ & $\begin{array}{l}22.2 \%^{\circ} \\
(21.3 \%, 23.0 \%)\end{array}$ & I \\
\hline
\end{tabular}

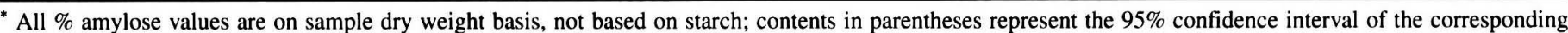
mean measured amylose value.

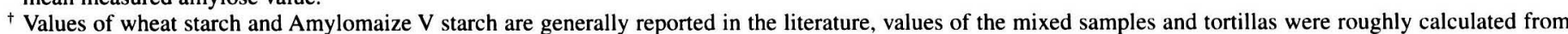
the formula.

a Values were calculated based on the overall standard curve for cereal starch sources for each method

b Values were calculated using the standard curve suitable for wheat and corn starch sources.

c Confidence intervals are "fiducial" $95 \%$ confidence intervals for predicted amylose values using corresponding standard curves.

d Values were calculated using the equation specific for the Megazyme amylose/amylopectin kit, $95 \%$ confidence intervals were based on 4 measured values.

e. f. g, h, i. j. k. m. n. and o Within each sample, results from different methods with the same superscript were not significantly different (P $>0.05$ ). 
the "true" value; another reason (relative to HPSEC) was the starch polymer dispersion problem. If using a set of highly pure native starch samples with known amounts of amylose as amylose standards, and given a well-controlled starch dispersion method when using the HPSEC procedure, the measured results for simple starch systems using these four amylose methods might not be significantly different from each other. Unfortunately, even under such limitations, for a given sample, the measured value using these different methods could still be different. "Amylose" is a mixture of a broad range of polymers with different molecular weights and configurations. Given the different physical/chemical principles associated with each amylose determining method, the real definition of amylose detected using each method would also be different.

\section{Effect of Mixed Starches and a Tortilla System}

Moisture contents of Amylomaize V starch, wheat flour, wheat starch, and waxy starch were $10.6,11.8,15.4$, and $7.4 \%$, respectively. The total starch content of the Buccaneer wheat flour was 74.5\% (dry basis) (data from SERVTech Laboratories, Hastings, NE). The tortilla had $88.4 \%$ wheat flour content (dry basis) and a $96.1 \%$ wheat flour content without shortening. Using the amylose contents of the three base samples (Amylomaize V, flour, and waxy wheat starch) measured using DSC, iodine binding, HPSEC, and Megazyme amylose/amylopectin kit, amylose contents of the other five samples were derived accordingly within each amylose procedure and compared with the measured values (Table V).

The HPSEC procedure was not applicable to a mixed or system containing processed starch. There were several noticeable differences between measured and derived \% amylose values. Also, the Megazyme procedure was not very accurate when measuring the tortilla sample (representing a food system with other components besides starch). The DSC and iodine binding procedures were applicable to all samples tested without any significant difference between the measured values and derived values. Unexpectedly, the high shortening level in tortilla did not seem to interfere with these testing procedures. When using dual wavelengths, the iodine binding procedure yielded the least difference between measured and derived $\%$ amylose values. Once a standard curve is generated for cereal starches, this iodine binding method appears applicable to both multiple cereal starches mixtures and food systems containing cereal starch over a wide range of amylose contents.

\section{CONCLUSIONS}

When measuring the standard amylose sample set to generate standard curves, the DSC, iodine binding, and HPSEC procedures were all reproducible. A good linear relationship between analytical response and amylose content was obtained within each starch source for each measuring method; the range of amylose contents measured did not affect these procedures. When using DSC and iodine binding methods, starches from cereal sources did not have significant differences in their responses; an overall standard curve for cereal starches was applicable. Potato starch acted differently. When interpreting the HPSEC data by dividing amylose peak area values with total peak areas, although the standard curve slopes for all the starches were the same, an overall cereal standard curve was not applicable.

Using the value of the detected amylose mass divided by total injected starch mass, however, reduced susceptibility of HPSEC to differences in sample dispersion and enabled the generation of an overall standard curve for cereal starches. Adding a test wavelength $(510 \mathrm{~nm})$ to the traditional single $620 \mathrm{~nm}$ wavelength during the iodine binding procedure greatly increased accuracy and precision of the method.

When testing additional selected samples, these four methods yielded different results. The DSC, iodine binding using $620 \mathrm{~nm}$, and Megazyme procedures were highly correlated. The DSC method and iodine binding method using $620 \mathrm{~nm}$ tended to overestimate the $\%$ amylose in all starch samples.

TABLE IV

Difference Between Dual Wavelength Method and Other Procedures (Method \% Amylose - Dual Wavelength \% Amylose)

\begin{tabular}{|c|c|c|c|c|c|c|}
\hline Sample & DSC & $\begin{array}{l}\text { Iodine } \\
\text { (620 nm) }\end{array}$ & HPSEC Cal (A) & HPSEC Cal (B) & Megazyme & $\begin{array}{l}\text { Iodine Dual } \\
(620 / 510)^{\mathrm{a}}\end{array}$ \\
\hline Amylomaize V starch & 15.3 & 20.9 & -3.2 & -13.4 & -6.2 & 48.6 \\
\hline Waxy wheat starch & -4.5 & 7.4 & -13.7 & -7.3 & 2.9 & 1.5 \\
\hline Wheat flour & 10.7 & 5.2 & -0.1 & -18.12 & -3.0 & 22.9 \\
\hline Wheat starch & 15.4 & 8.7 & -4.4 & -12.4 & -7.3 & 31.4 \\
\hline Wheat starch + waxy wheat starch & 0.2 & 6.4 & -5.2 & -9.4 & -2.9 & 16.0 \\
\hline Amylomaize V + wheat starch & 15.5 & 9.9 & 0.2 & -15.6 & -6.2 & 41.0 \\
\hline Nondefatted tortilla & 11.8 & 3.9 & 43.1 & -8.5 & 3.1 & 19.5 \\
\hline Defatted tortilla & 9.8 & 3.8 & 5.8 & -0.3 & - & 22.5 \\
\hline
\end{tabular}

a Calculated \% amylose using iodine dual wavelength method; values in other columns represent the difference between the dual wavelength method and the listed procedures (method $\%$ amylose - dual wavelength $\%$ amylose).

TABLE V

Amylose Measuring Methods: Applicability to Mixed and Processed Starch Samples ${ }^{2-d}$

\begin{tabular}{|c|c|c|c|c|c|c|c|c|c|c|c|c|}
\hline \multirow[b]{2}{*}{ Sample } & \multicolumn{2}{|c|}{ DSC } & \multicolumn{2}{|c|}{ Iodine 620nm } & \multicolumn{2}{|c|}{ Iodine Dual (620/510) } & \multicolumn{2}{|c|}{ HPSEC Cal (A) } & \multicolumn{2}{|c|}{ HPSEC Cal (B) } & \multicolumn{2}{|c|}{ Megazyme } \\
\hline & Derv & Diff & Derv & Diff & Derv & Diff & Derv & Diff & Derv & Diff & Derv & Diff \\
\hline Wheat starch & 45.1 & 1.7 & 37.7 & 2.4 & 30.7 & 0.7 & 30.6 & -3.6 & 6.3 & $12.6 *$ & 26.7 & -2.7 \\
\hline Wheat starch + waxy wheat starch & 19.9 & -3.7 & 22.7 & -0.2 & 15.4 & 0.5 & 8.2 & 2.6 & 0.0 & $3.53 *$ & 15.1 & -2.0 \\
\hline Amylomaize V + wheat starch & 54.8 & 1.7 & 54.0 & -3.2 & 39.9 & 1.0 & 38.2 & 2.9 & 21.2 & 4.17 & 34.7 & 0.0 \\
\hline Nondefatted tortilla & 29.7 & 1.6 & 24.8 & -1.4 & 20.2 & -0.7 & 20.2 & 42.4* & 4.2 & 6.87 & 17.6 & $5.1^{*}$ \\
\hline Defatted tortilla & 32.3 & 0.1 & 27.0 & -0.7 & 22.00 & 0.5 & 21.9 & $6.4 *$ & 4.5 & $17.65^{*}$ & - & - \\
\hline
\end{tabular}

a All \% amylose values were on dry sample basis.

${ }^{b}$ Formula-derived \% amylose (Derv), based on measured values of three original samples (Amylomaize V starch, waxy wheat starch, and wheat flour) (directly measured $\%$ amylose values referred to in Table III).

c Measured \% amylose minus formula derived \% amylose (Diff).

$\mathrm{d} *$, Indicates significant difference $(P<0.05)$. 
Generating standard curves using common amylose standards or adjusting the results to a given standard could allow for more reliable amylose determinations. However, when using dual wavelengths at 620 and $510 \mathrm{~nm}$, the iodine binding method appeared to correct this problem and increase the precision and accuracy of the method. The iodine binding and DSC procedures were useful for measuring samples containing different starch sources and samples with different amylose content ranges; they were also applicable to the tortilla system. The Megazyme amylose/amylopectin kit was more variable when measuring the tortilla system. HPSEC procedures were not reliable, especially when the samples were not pure starch.

The iodine binding procedure using wavelengths at both 620 and $510 \mathrm{~nm}$ is highly recommended for its good reproducibility and applicability to mixed starch samples and the tortilla samples. Also, this procedure can be performed on multiple samples simultaneously. However, disadvantages are that it is time-consuming and rather complicated. The DSC method is outstanding for its convenience in testing a small number of samples and it is not as susceptible to nonstarch components. The Megazyme amylose/ amylopectin kit is extremely time-consuming and needs precise experimental control. It was not very applicable for measuring the amylose content in the tortilla system. The kit's biggest advantage, however, is there is no standard curve generation involved. Amylose contents can be directly measured. Although the HPSEC method can separate amylose and amylopectin, it is susceptible to sample dispersion problems, especially with nonstarch components. It is the least useful method to reliably test amylose contents.

\section{LITERATURE CITED}

AACC International. 2000. Approved Methods of the American Association of Cereal Chemists, 10th Ed. Methods 38-10 and 44-15A. The Association: St. Paul, MN

Bates, F. L., French, D., and Rundel, R. E. 1943. Amylose and amylopectin content of starches determined by their iodine complex formation. J. Am. Chem. Soc. 65:142-148.

Bjöck, I., Eliasson, A.-C., Drews, A., Gudmundsson, M., and Karisson, R. 1990. Some nutritional properties of starch and dietary fiber in barley genotypes containing different levels of amylose. Cereal Chem. 67:327-333.

Chinnaswamy, R., and Hanna, M. A. 1988. Relationship between amylose content and extrusion expansion properties of corn starches. Cereal Chem. 65:138-143.

Gibson, T. S., McCleary, B. V., and Solah, V. A. 1995. Con A revisitedA simplified assay to measure amylose in cereal starches. Pages $162-$ 165 in Proc. 45th Australian Cereal Chem. Conf. Y. A. Williams and C. W. Wrigley, eds. RACI: Melbourne.

Gibson, T. S., Solah, V. A., and McCleary, B. V. 1997. A procedure to measure amylose in cereal starches and flours with Concanavalin A. J. Cereal Sci. 25:111-119.

Himmelsbach, D. S., Barton, II, F. E., McClung, A. M., and Champagne, E. T. 2001. Protein and apparent amylose contents of milled rice by NIR-FT/Raman spectroscopy. Cereal Chem. 78:488-492.

Jackson, D. S. 1991. Solubility behavior of granular corn starches in methyl sulfoxide (DMSO) as measured by high performance size exclusion chromatography. Starch/Starke 43:422-427.

Jane, J., Chen, Y. Y., Lee, L. F., McPherson, A. E., Wong, K. S., Radonsavljevic, M., and Kasemsuwan, T. 1999. Effects of amylopectin branch chain length and amylose content on the gelatinization and pasting properties of starch. Cereal Chem. 76:629-637.

Lee, M.-R., Swanson, B. G., and Baik, B.-K. 2001. Influence of amylose content on properties of wheat starch and breadmaking quality of starch and gluten blends. Cereal Chem. 78:701-706.

McGrance, S. J., Comell, H. J., and Rix, C. J. 1998. A simple and rapid colorimetric method for the determination of amylose in starch products. Starch/Starke 50:158-163.

Mestres, C., Matencio, F., Pons, B., Yajid, M., and Fliedel, G. 1996. A rapid method for the determination of amylose content by using differential scanning calorimetry. Starch/Starke 48:2-6.

Mua, J. P., and Jackson, D. S. 1998. Retrogradation and gel textural attributes of corn starch amylose and amylopectin fractions. J. Cereal Sci. 27:157-166.

Russel, P. L., Berry, C. S., and Greenwell, P. 1989. Characterization of resistant starch from wheat and maize. J. Cereal Sci. 9:1-15.

Wehling, R. L., Jackson, D. S., Hooper, D. G., and Ghaedian, A. R. 1993. Prediction of wet-milling starch yield from corn by near-infrared spectroscopy. Cereal Chem. 70:720-723.

Williams, V. R., Wu, W. T., Tasi, H. Y., and Bates, H. G. 1958. Varietal differences in amylose content of rice starch. J. Agric. Food Chem. 6:47-48.

You, S.-G., and Lim, S.-T. 2000. Molecular characterization of corn starch using an aqueous HPSEC-MALLS-RI system under various dissolution and analytical conditions. Cereal Chem. 77:303-308.

Yun, S. H., and Matheson, N. K. 1990. Estimation of amylose content of starches after precipitation of amylopectin by concanavalin-A. Starch/ Starke 42:302-305.

[Received March 6, 2007. Accepted August 21, 2007.] 